\title{
Shell thinning due to embryo development in eggs of a small passerine bird
}

\author{
Grzegorz Orłowski $^{1}$ - Lucyna Hałupka ${ }^{2}$ Ewelina Klimczuk ${ }^{3} \cdot$ Hanna Sztwiertnia $^{2}$
}

Received: 5 June 2015/Revised: 13 August 2015/Accepted: 31 August 2015/Published online: 21 September 2015

(C) The Author(s) 2015. This article is published with open access at Springerlink.com

\begin{abstract}
Over four study years we have investigated hatching success and failure, the presence of an embryo and other egg biometrics, and eggshell thickness of the Eurasian Reed Warbler Acrocephalus scirpaceus. Of 1354 eggs from 350 nests, $940(69.4 \%)$ survived until hatching, of which $159(16.9 \%)$ were incubated but failed to hatch, while 273 (20.2\% of all) were in nests destroyed during incubation. Of 161 intact unhatched eggs from 97 nests, 64 (39.8\%) had no visible embryo and $88(54.7 \%)$ had a visible embryo. Eggs without visible embryos were present in $42.7 \%$ of normally incubated clutches; among deserted clutches over $50 \%$ had no visible embryo. Eggshell thickness at the egg equator (the widest part) was negatively correlated with clutch size and the presence of an embryo. A similar relationship was found for the blunt end of the eggs but was not statistically significant. Shells at the equator of eggs with visible embryos were significantly thinner (on average $8.0 \%$ less) than the shells of eggs without embryos. Our study clearly implies that shell thickness decreases in the course of embryonic development. It also indicates that comparison of eggshell thickness data without controlling for the presence of an embryo in eggs can produce biased results, and may, therefore, fail
\end{abstract}

Communicated by F. Bairlein.

Grzegorz Orłowski

orlog@poczta.onet.pl

1 Institute of Agricultural and Forest Environment, Polish Academy of Sciences, Bukowska 19, 60-809 Poznan, Poland

2 Ornithological Station, Faculty of Biology, University of Wrocław, Sienkiewicza 21, 50-335 Wrocław, Poland

3 Museum of Natural History, Faculty of Biology, University of Wrocław, Sienkiewicza 21, 50-335 Wrocław, Poland to identify the actual causes of eggshell thinning. Our findings also suggest that shell thickness at the blunt end is a reliable estimator of shell thickness, irrespective of embryonic development.

Keywords Hatching failure - Avian eggs - Embryo development · Infertile eggs · Eggshell thinning ·

Acrocephalus scirpaceus

\section{Zusammenfassung}

Verdünnung der Eischale als Folge der Embryonalentwicklung bei einem kleinen Singvogel

Über einen Zeitraum vier Jahre haben wir den Schlupferfolg, die Anwesenheit eines Embryos, weitere Eimaße und die Eischalendicke von Teichrohrsaengern (Acrocephalus scirpaceus) untersucht. Von 1354 Eiern aus 350 Nestern sind $940(69.4 \%)$ erfolgreich geschlüpft, $159(16.9 \%)$ waren bebrütet schlüpften aber nicht, und 273 (20.2\%) wurden während der Bebrütung zerstört. Aus 161 intakten unbebrüteten Eiern (97 Nester) hatten 64 (39.8\%) keinen und $88(54.7 \%)$ einen sichtbaren Embryo. $42.7 \%$ der normal bebrüteten und $50 \%$ der verlassenen Eier waren ohne sichtbaren Embryo. Die Dicke der Eierschale, gemessen am Eierschalenäquator (der breiteste Durchmesser), korrelierte negativ mit der Gelegegröße und der Anwesenheit eines Embryo. Ein ähnlicher Zusammenhang zeigte sich für das stumpfe Ende des Eies, doch war dieser nicht statistisch signifikant. Eier mit sichtbarem Embryo waren an ihrem Äquator signifikant durchschnittlich $8 \%$ dünner als Eier ohne Embryo. Unsere Studie zeigt, dass die Dicke der Eierschale während der Embryonalentwicklung abnimmt. Dies weist zudem darauf hin, dass Vergleiche von Eischalendicken ohne Berücksichtigung der 
Anwesenheit eines Embryos zu fehlerhaften Ergebnissen führen und deshalb die wirklichen Ursachen für Eischalenverdünnungen nicht erkennen können. Unsere Ergebnisse weisen auch daraufhin, dass die Eischalendicke am stumpfen Ende des Eies die Eischalendicke zuverlässiger wiedergibt, ungeachtet von der Embryonalentwicklung.

\section{Introduction}

Studies of variation in eggshell thickness are of importance for understanding both the quality of shells in wild and domestic birds, as well as in the context of the impact of anthropogenic factors such as pollution or other environmental stressors (Hoffman et al. 2003; Maurer et al. 2012). There is a growing interest in the thinning of avian eggshells as an effect of pollution, primarily by the environmental derivative of the insecticide DDT (Risebrough 1986; Jagannath et al. 2008; Miljeteig et al. 2012). Eggshell thinning may also be related to calcium deficiency (Eeva and Lehikoinen 1995; Reynolds 2001), or female characteristics (Hargitai et al. 2011).

As a result of calcium reabsorption from the eggshell by the developing embryo to satisfy its requirements, shells show progressive thinning (hereafter: natural eggshell thinning) caused by the erosion of the inner (mammillary) surface of the shell (Deeming 2002; Castilla et al. 2010). Such a decrease in eggshell thickness as an effect of embryo formation (or its further development) has been reported in several bird species, both altricial and precocial (e.g., Rothstein 1972; Pulliainen and Marjakangas 1980; Bunck et al. 1985; Castilla et al. 2010). In addition, several other studies have shown that regional (i.e., specific to certain areas of the eggshell) differences exist in shell thickness, conductance, and pore structure in a particular bird species (Booth 1989; Handrich 1989; Kern et al. 1992; Balkan et al. 2006; Maurer et al. 2011a, b). Moreover, these properties change throughout the period of incubation (Booth 1989; Balkan et al. 2006; Castilla et al. 2010; Maurer et al. 2011b). Calcium absorption by a developing embryo can variably decrease shell thickness, with pronounced thinning occurring at the sharp pole compared to the equator and blunt end of an egg (Booth 1989; Kern et al. 1992; Maurer et al. 2011b). As such, the consideration of intrinsic factors postulated to affect shell properties, such as its thickness, is crucial for distinguishing external environmental effects from developmental shell thinning processes (Rothstein 1972; Pulliainen and Marjakangas 1980; Bunck et al. 1985).

Since many recent studies on the variability of avian eggshell thickness (primarily for ecotoxicological analyses) have been based on deserted eggs or clutches (e.g., Falk and
Møller 1990; Jagannath et al. 2008; Odsjö and Sondell 2014), and these samples may include a variable number of eggs at various developmental stages, another important question is the relationship between the presence of embryonic development in eggs ( $\approx$ fertility) and shell thickness. In populations of wild birds, hatching failure may result from a variety of factors, such as food and calcium availability (reviewed in Reynolds and Perrins 2010), but also latitudinal gradient, weather conditions, temperature, or humidity. Other important factors may be nest type, quality and age of parents and/or genetic incompatibility (Koenig 1982; Birkhead et al. 2008; Stewart and Westneat 2013). Importantly, the majority of studies of hatching failure did not determine the contribution of non-embryonated eggs and so failed to distinguish between infertility (i.e., absence of an embryo) and embryo mortality (Potti and Merino 1996; Birkhead et al. 2008; Hemmings et al. 2012). Analogously, in the majority of previous studies on changes in eggshell thickness due to embryo development, eggs were described as 'unhatched', 'unincubated' or 'deserted', while their developmental state and/or presence of an embryo were not classified unequivocally. Given previous findings that eggs without embryonic development have significantly thicker shells than embryonated ones (Booth and Seymour 1987; Castilla et al. 2007, 2010), it may be assumed the proportion of each egg category might explain a large part of the variability in eggshell thickness within a sample of eggs of individual bird species.

Another equally important problem is associated with the reduction in shell thickness throughout the incubation period (Finnlund et al. 1985; Maurer et al. 2011a). For example, it has been shown that 3-5 days of incubation were sufficient to reduce eggshell weight by 7-14\% in galliform birds (Bennett 1995; Castilla et al. 2007). This may mean that in some species embryonic development can induce a reduction in shell density (sensu Karlsson and Lilja 2008) rather than in shell thickness. On the other hand, it can also be assumed that the lack of a clear relationship between eggshell thickness and embryo development in some previous studies (e.g. Burnham et al. 1984; Falk and Møller 1990; Bennett 1995; but see contradictory positive results for the same or related species: Handrich 1989; Balkan et al. 2006; Castilla et al. 2010), may have resulted from the examination of eggs with relatively well developed embryos and/or samples with few or no nonembryonated/infertile eggs. This potential explanation for the lack of a significant relationship between eggshell thickness and embryo development was previously mentioned by some researchers (Anderson and Hickey 1970; Castilla et al. 2010; Miljeteig et al. 2012).

The present study addresses the above issues by investigating the relationship between the presence of embryonic development and eggshell thickness data in a population of a small passerine bird, the Eurasian Reed 
Warbler A. scirpaceus (hereafter Reed Warbler). We present new data on hatching failure, the percentage of embryonated and non-embryonated eggs, biometrics of eggs, and shell thickness. These data were used to analyse relationships with various physiological/morphological correlates of individual females (e.g., age, size and body condition) and several characteristics of an egg (e.g., size, volume, mass, order within a clutch, and clutch size). We hypothesized that eggshell thickness could be correlated directly with egg size (e.g., Snyder and Meretsky 2003) or female size, or indirectly with female body condition and clutch features (Burnham et al. 1984; Falk and Møller 1990; Castilla et al. 2010; Hargitai et al. 2011). In addition, we predicted that the range of changes in eggshell thickness may vary across the regions of an egg over developmental time as a result of the variable utilization of calcium by a developing embryo (Kern et al. 1992; Castilla et al. 2010; Maurer et al. 2011a, b).

\section{Methods}

The study was carried out in May-August of 2010-2013 on the Słoneczny fishpond $\left(51^{\circ} 32^{\prime} \mathrm{N}, 17^{\circ} 20^{\prime} \mathrm{E}\right)$ in the Stawy Milickie Nature Reserve (SW Poland) as part of an extensive project conducted since 2005 . The 4 ha study plot comprised an extensive reed-bed (up to $150 \mathrm{~m}$ wide) with a system of bays and channels within. The dominant plant species was the common reed Phragmites australis, but in some places bittersweet Solanum dulcamara and cattails Typha angustifolia were also abundant. The studied nests were situated $10-120 \mathrm{~m}$ from the dike overgrown with trees and bushes, which were frequently used as foraging sites by Reed Warblers (Król 1984). Differences in nest locations could affect calcium availability for different females; however, this aspect was not studied.

Throughout the breeding season, we mist-netted and colour-ringed adult Reed Warblers. We weighed them to the nearest $0.5 \mathrm{~g}$ (Pesola $30 \mathrm{~g}$ spring scales, PCE Instruments), and measured their flattened wing cord to the nearest $0.5 \mathrm{~mm}$ (ornithological ruler, Ecotone). A small amount of blood was obtained by brachial venipuncture with a $0.45 \mathrm{~mm}$ needle, and about $10 \mu \mathrm{l}$ of blood was collected directly into a microcuvette for a HemocueHb 201+ photometer (AB Leo Diagnostics, Helsingborg, Sweden) to measure $\mathrm{Hb}$ concentration in venous blood. Parental birds were identified at nests by observing nestbuilding behaviour and by video-recording each nest. Full details about study procedures are presented elsewhere (Halupka et al. 2008, 2014a, b).

On average $( \pm \mathrm{SD})$ clutches comprised $3.97( \pm 0.74)$ eggs (range 2-6 eggs). Most nests (about $85 \%$ ) were found at the building stage and were visited daily during laying.
On the day of laying, the blunt end of each successive egg was marked with a small dot of a different colour using a non-toxic marker, and each egg was weighed to the nearest $0.01 \mathrm{~g}$. Before the expected day of hatching (generally 11 days after the last egg had been laid; Klimczuk et al. 2015), nests were visited daily to determine the day of hatching of the first nestling(s). We collected unhatched eggs generally 5 days after hatching of the first nestlings (the maximum hatching spread found in our population was $54 \mathrm{~h}$; L. Hałupka, unpubl. data).

A total of 161 unhatched eggs were collected from 97 nests, including 68 nests where females were identified. The laying order was known for 140 eggs. After collection, the length and width of each unbroken egg were measured to the nearest $0.01 \mathrm{~mm}$. The egg volume was calculated using the equation given by Hoyt (1979): volume $\left(\mathrm{mm}^{3}\right)=0.51 \times$ length $\times$ breadth $^{2}$, where the length and breadth of an egg are expressed in $\mathrm{mm}$. Thereafter each egg was kept in a small plastic bag and frozen at $-20{ }^{\circ} \mathrm{C}$.

After thawing, each egg was opened along its widest part (the equator, or shoulder, according to Gosler et al. 2005), and the contents were placed in a glass dish before examination for the presence of an embryo. The sampled eggs were then classified into two categories: eggs without visible embryos (no embryo present in the yolk; presumably infertile) and eggs with visible embryos (an embryo present in the yolk). We decided not to classify eggs the contents of which had partially decomposed.

After cleaning the eggs by removing visible external dirt and any remnants of egg content, one of the co-authors (H.S.) measured the eggshell thickness to $10 \mu \mathrm{m}$ at three equidistant locations around the equator (located at the widest point of an egg), and at the blunt end of the most distant point of the egg pole using a micrometer (Mitutoyo, Mizonokuchi, Japan). Because of the small size of the sharp end of Reed Warbler eggs and the resulting difficulties in removing egg remnants therefrom, measurement of shell thickness at this area of the eggs did not yield reliable measurements; we did not takesuch measurements. The average of the three measurements at the egg equator was calculated to obtain the overall measurement of eggshell thickness in this area of the egg, with a single measurement representing shell thickness at the blunt end; hereafter, these values are presented as equator and blunt end shell thickness. All measurements were conducted with the inner membrane of the egg present.

\section{Statistical analyses}

To explore differences in shell thickness between eggs with and without visible embryos we used simple statistical methods, previously applied in similar studies, where eggs were pooled across all specimens or broods and were 
classified into two categories, i.e., non-embryonated (infertile) eggs and embryonated (fertile) eggs (e.g., Rothstein 1972; Finnlund et al. 1985; Balkan et al. 2006). For all eggs we assessed the differences in shell thickness between the blunt end and equator within each egg using a paired sample $t$ test. We then repeated the analysis within the subsamples of eggs with and without visible embryos.

The relationship between measurements of blunt end and equator eggshell thickness, and each of the 12 potential explanatory variables of clutch, females, and eggs (detailed in Table 1), was assessed using Spearman's rank correlation. Furthermore, to explore the relationship between blunt end and equator shell thickness, we produced a linear regression with the General Linear Model (GLM) (StatSoft 2007). GLM was also used to explore the effect of clutch size on the measurements of blunt end and equator shell thickness, and to assess the difference in blunt end and equator shell thickness between eggs with and without visible embryos.

Additionally, to avoid pseudoreplication (sensu Hurlbert 1984) resulting from analysing several eggs from the same brood, we averaged the eggshell thickness data per individual brood by calculating separate values for eggs with and without visible embryos. After this treatment, we obtained data representing 51 and 35 broods for each group of eggs, respectively.

Analyses were performed using Statistica 7.0 (StatSoft 2007). The probability of $P<0.05$ was assumed to be statistically significant.

\section{Results}

Over the 4 years of field studies we found 350 active nests of Reed Warblers containing 1354 eggs; of these nests, 76 $(21.7 \%)$ were depredated, $17(4.9 \%)$ parasitized by the
European Cuckoo Cuculus canorus and 11 (3.1\%) were abandoned. The remaining 246 nests (66.7-73.3\% a year), containing 940 eggs, were active until hatching. Each year, unhatched eggs were recorded in 33.3-55.7\% of successful nests (i.e., nests not depredated before hatching), and unhatched eggs constituted $16.9 \%$ of the total number of eggs surviving until hatching. All unhatched eggs, if they remained in the nest, were included in the analysis.

Among 161 unhatched eggs we identified 64 (39.8\%) without visible embryos and 88 (54.7\%) with visible embryos (at various developmental stages); the remaining 9 eggs $(5.6 \%)$ were not classified because they were damaged.

\section{Eggshell thickness and embryo development in Eurasian Reed Warblers}

Pair-wise comparison of shell thickness measurements within the same unhatched eggs showed remarkable differences between the blunt end and equator. Overall, the shells of all eggs were significantly thinner (on average by $9.5 \%$ ) at the equator compared to the blunt end (Table 1) (paired sample test: $t=8.06, P<0.0001, n=151$ ).

Analysis of the relationships between eggshell thickness data and various features of clutches, females, and eggs (Table 1) showed relatively weak associations (Table 2). Eggshell thickness at the equator was negatively correlated with clutch size and the presence of an embryo (both relationships are analysed in more detail below). The strongest relationship was obtained between blunt end thickness and equator thickness (Table 1). Additionally, the linear regression output showed that $24 \%$ of the variability of blunt end thickness or equator thickness was explained by the one of these variables (GLM, $r^{2}=0.241$, $\left.F_{1,152}=47.6, P<0.0001\right)$.
Table 1 Descriptive statistics of variables of clutch, females, eggs, and eggshell thickness for 161 sampled unhatched eggs of Eurasian Reed Warbler Acrocephalus scirpaceus, containing eggs without visible embryos and eggs with visible embryos collected between 2010 and 2013 in the Stawy Milickie Nature Reserve (SW Poland)

\begin{tabular}{llllll}
\hline Variable (unit) & $n$ & Average & SE & $-95 \%$ CL & +95 \% CL \\
\hline First egg laying date (531 = 31 May) & 161 & 611 & 5 & 601 & 621 \\
Clutch size & 145 & 4.01 & 0.06 & 3.89 & 4.14 \\
Clutch of a female in a season & 160 & 1.48 & 0.06 & 1.36 & 1.59 \\
Female age (years old) & 113 & 1.44 & 0.08 & 1.29 & 1.59 \\
Female weight (g) & 90 & 12.68 & 0.11 & 12.46 & 12.91 \\
Female wing length (mm) & 89 & 65.36 & 0.15 & 65.06 & 65.66 \\
Female Hb & 85 & 157.34 & 1.39 & 154.58 & 160.10 \\
Egg order at a given nest & 141 & 2.27 & 0.10 & 2.06 & 2.48 \\
Egg length (mm) & 140 & 18.62 & 0.07 & 18.48 & 18.76 \\
Egg width (mm) & 142 & 13.68 & 0.04 & 13.60 & 13.75 \\
Egg volume (mm ${ }^{3}$ ) & 140 & 1780.1 & 14.1 & 1752.9 & 1808.7 \\
Egg mass (g) & 112 & 1.90 & 0.02 & 1.87 & 1.94 \\
Eggshell thickness at blunt end (mm) & 154 & 0.103 & 0.001 & 0.101 & 0.106 \\
Eggshell thickness at equator $(\mathrm{mm})$ & 152 & 0.093 & 0.001 & 0.092 & 0.095
\end{tabular}


Table 2 Spearman's rank correlation coefficients between shell thickness measured at the blunt end and equator of eggs, and variables of clutch, females and eggs in Reed Warbler Acrocephalus scirpaceus; statistically significant relationships are marked in bold

\begin{tabular}{|c|c|c|c|c|c|c|}
\hline \multirow[t]{2}{*}{ Variable } & \multicolumn{3}{|c|}{ Blunt end thickness } & \multicolumn{3}{|c|}{ Equator thickness } \\
\hline & $n$ & $r_{\mathrm{s}}$ & $P$ value & $n$ & $r_{\mathrm{s}}$ & $P$ value \\
\hline First egg laying date & 154 & 0.149 & 0.065 & 152 & 0.065 & 0.425 \\
\hline Clutch size & 139 & -0.123 & 0.149 & 138 & $-\mathbf{0 . 1 9 3}$ & 0.024 \\
\hline Clutch of a female in a season & 153 & 0.189 & 0.019 & 151 & 0.150 & 0.066 \\
\hline Female age & 108 & -0.007 & 0.942 & 107 & -0.055 & 0.572 \\
\hline Female weight & 85 & 0.110 & 0.317 & 85 & -0.024 & 0.825 \\
\hline Female wing length & 84 & 0.225 & 0.040 & 84 & 0.085 & 0.440 \\
\hline Female $\mathrm{Hb}$ & 80 & -0.029 & 0.799 & 80 & -0.147 & 0.192 \\
\hline Egg order at a given nest & 134 & 0.006 & 0.949 & 132 & -0.070 & 0.422 \\
\hline Egg length & 137 & 0.086 & 0.319 & 136 & 0.043 & 0.617 \\
\hline Egg breath & 139 & -0.063 & 0.463 & 138 & 0.009 & 0.912 \\
\hline Egg volume & 137 & -0.015 & 0.864 & 136 & 0.007 & 0.938 \\
\hline Egg mass & 105 & 0.020 & 0.836 & 104 & -0.030 & 0.763 \\
\hline Presence of embryo & 147 & -0.131 & 0.113 & 145 & -0.342 & 0.001 \\
\hline Eggshell thickness at equator & 152 & 0.470 & 0.000 & - & - & - \\
\hline
\end{tabular}

Shell thickness at both the blunt end and the equator of all sampled eggs showed a progressive decrease attributable to increasing clutch size (Fig. 1a), but this trend was significant only for equator thickness (GLM, $r^{2}=0.166$, $F_{4,133}=4.4, P<0.002$ ), and not the blunt end (GLM, $\left.r^{2}=0.048, \quad F_{4.134}=1.7, \quad P=0.155\right) . \quad$ Further, we observed no significant interaction between clutch size and blunt end thickness $\times$ presence of embryo (GLM, $\left.F_{9,123}=0.3, P=0.879\right)$ or between clutch size and equator thickness $\times$ presence of embryo (GLM, $\left.F_{9,123}=2.0, P=0.094\right)$. Analogously, in none of the sampled eggs (Fig. 1b) did we observe any significant effect of egg laying sequence on shell thickness at the blunt end (GLM, $r^{2}=0.08, F_{5,128}=2.2, P=0.06$ ) and equator (GLM, $\left.r^{2}=0.07, F_{5,126}=1.9, P=0.100\right)$. Similarly, further interactions between egg laying sequence and blunt end thickness or equator thickness $\times$ presence of embryo yielded no significant effects $(P=0.572$ and 0.972 , respectively). Shell thickness data for all eggs (without regard for the presence of an embryo), as presented in Fig. 1, are representative of the categories of clutch size or egg laying sequence in our egg sample.

We observed marked differences in eggshell thickness among all sampled eggs (Fig. 2). Shells at the equator of eggs with visible embryos were significantly thinner than those of infertile eggs (GLM, $r^{2}=0.109, F_{1,143}=17.5$, $P<0.0001$; Fig. 2). Overall, shell thickness at the equator of eggs without visible embryos was on average $8.0 \%$ more than in eggs with visible embryos (Fig. 2).

Repeated analysis of shell thickness based on data averaged per individual brood confirmed the previous results for all sampled eggs. The mean shell thickness at the equator of eggs without visible embryos $(n=35$ broods) was $96.97( \pm \mathrm{SE}=1.81) \mu \mathrm{m}$, while that of eggs
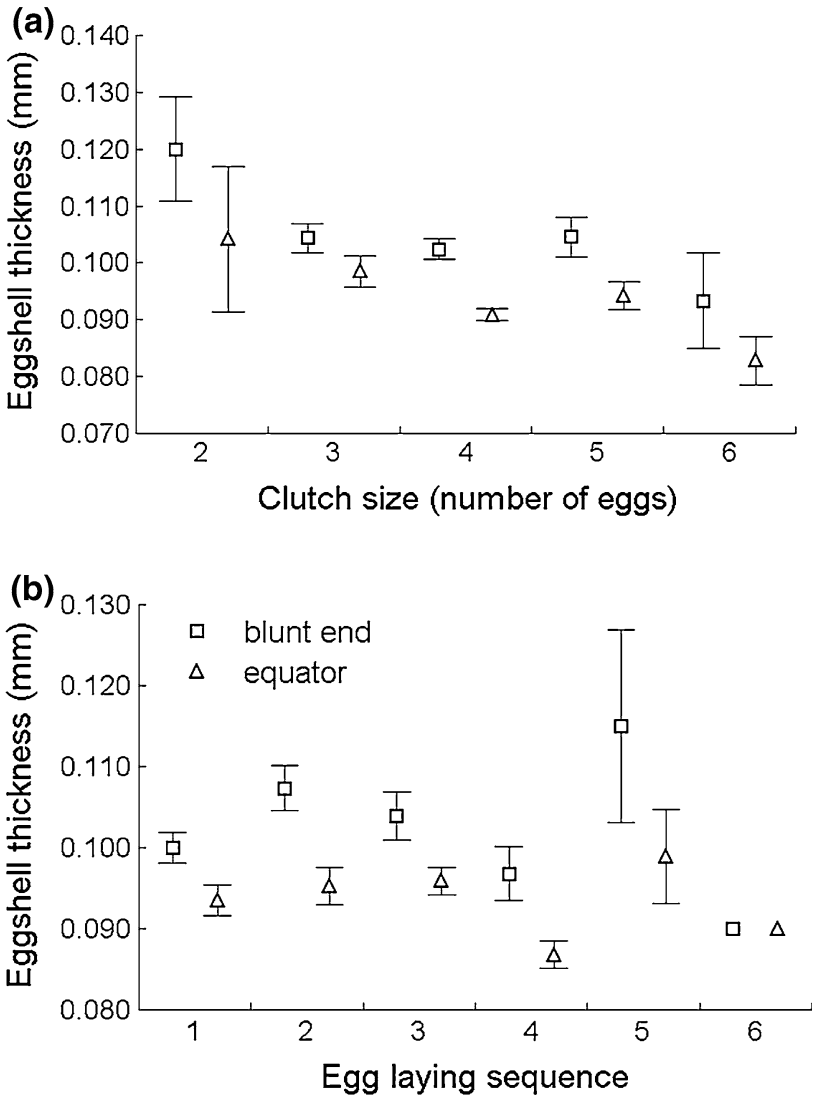

Fig. 1 Comparison of measurements of shell thickness (average $\pm 1 \mathrm{SE}$ ) at the blunt end and equator of all sampled eggs of Reed Warbler Acrocephalus scirpaceus in relation to clutch size (a) and laying sequence (b)

with visible embryos ( $n=51$ broods) was 90.27 $( \pm \mathrm{SE}=1.45) \mu \mathrm{m}$. Therefore, embryo formation caused an average of $6.9 \%$ eggshell thinning indexed by a 
Fig. 2 Comparison of shell thickness at the equator (a) and blunt end (b) of eggs without visible embryos and eggs with visible embryos of Reed Warbler Acrocephalus scirpaceus
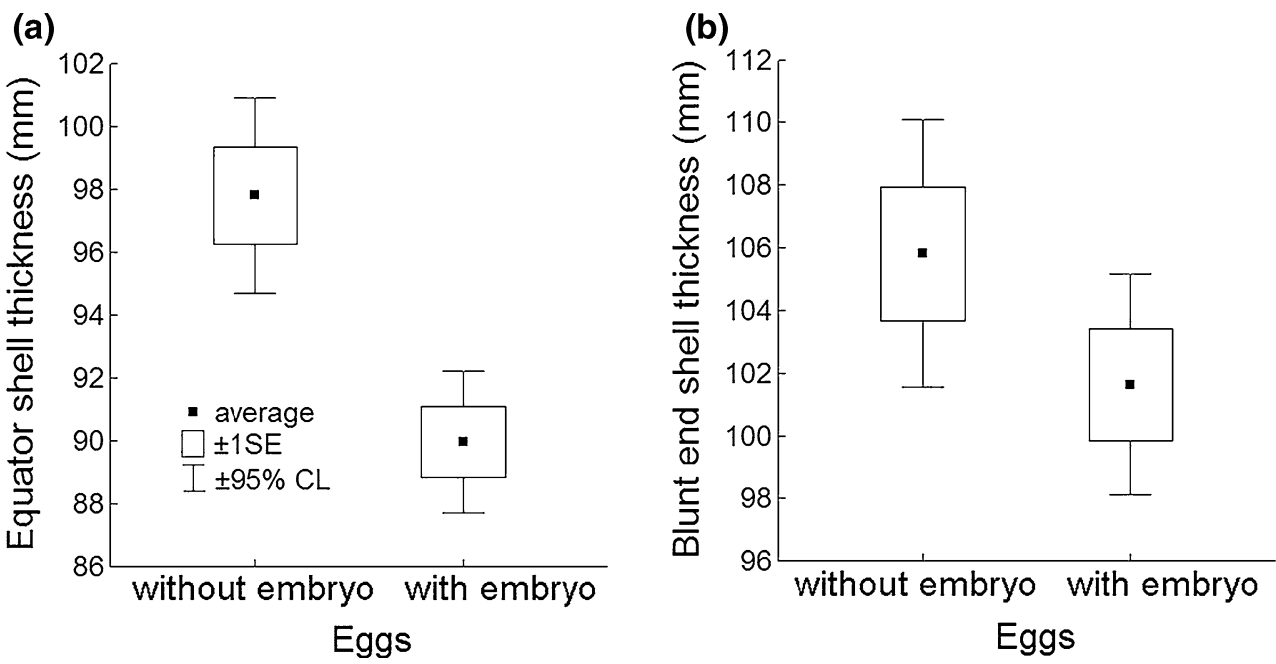

statistically significant difference in shell thickness between two categories of eggs: with and without visible embryos for our data averaged per individual brood (GLM, $\left.r^{2}=0.093, F_{1,84}=8.61, P=0.0043\right)$.

Comparison of shell thickness at the blunt end showed no statistically significant difference between eggs without visible embryos and eggs with visible embryos (GLM, $r^{2}=0.015, F_{1,145}=2.3, P=0.134$; Fig. 2), although the shells of eggs with visible embryos were on average $3.9 \%$ thinner than those of eggs without visible embryos (Fig. 2). Similarly, the average shell thickness of eggs without visible embryos and eggs with visible embryos was, respectively, 5.6 and $7.5 \%$ thinner at the equator compared to the blunt end, and both differences were statistically significant (paired sample test: $t=6.52$ and 4.67, $P<0.0001, n=89$ and 60 , in both cases, respectively).

\section{Discussion}

The most important result obtained in our study is the marked difference in eggshell thickness within the sample of unhatched Eurasian Reed Warbler eggs between eggs with and without visible embryos. This was especially clear for the egg equator area (where the chorioallantoic membrane occurs), but not for the blunt end, where the air cell forms between the inner and outer shell membranes. These findings confirm the previously described pattern of developmental eggshell thickness erosion (Booth 1989; Kern et al. 1992; Balkan et al. 2006; Maurer et al. 2011a).

The difference in eggshell thickness at the equatorial part of an egg due to embryo development reported in our study represents an intermediate value compared to other small passerines examined previously. The eggshell thickness of the Cedar Waxwing Bombycilla cedrorum (Rothstein 1972) and the Cliff Swallow Petrochelidon pyrrhonota (Sotherland et al. 1980) were found to be 5.4 and $5.6 \%$ thinner, respectively, while in the Pied Flycatcher Ficedula hypoleuca the shells were $29.0 \%$ thinner in eggs with embryonic development (Kern et al. 1992). Such large discrepancies among passerine birds of a similar body size suggest that some other factors (e.g., physiological state of females, season, site or resource availability, etc.) might be responsible for variable embryonic shell erosion. This conclusion gains support from some experimental studies, which demonstrated that calcium-supplemented birds laid larger, thicker-shelled eggs (reviewed in Reynolds and Perrins 2010). The most plausible explanation is that the decrease in searching time for calcium might incur a higher intake of nutrients or lower energy expenditure (Mänd and Tilgar 2003; Hargitai et al. 2011).

In general, our results showing the decrease in eggshell thickness with increasing clutch size seem to confirm some previous expectations of decreasing body calcium levels in egg-laying females (Burnham et al. 1984; Falk and Møller 1990; Reynolds 2001). However, we did not find the expected decline in shell thickness related to laying order. This could result from insufficient sample sizes (especially in the subsamples of the 5th and 6th egg), pooling the data representing eggs with and without embryos, as well as pooling the eggs from first and replacement clutches in a season (Reed Warbler may lay up to four clutches in a season).

Another interesting finding from our study is the positive relationship between female size, indexed by wing length, and blunt end shell thickness (not so susceptible to embryonic erosion). Overall, this finding agrees to some degree with previous observations that heavier females of Collared Flycatchers Ficedula albicollis lay eggs of a relatively larger size with thicker shells at the equator (Hargitai et al. 2011). 
Importantly, our findings concerning the embryo-induced decrease of eggshell thickness imply some critical applications for eggshell thinning studies. Since eggs without visible embryos have markedly thicker shells compared to eggs containing an embryo, the results of comparing eggshell thickness data for intact, addled eggs, without checking for the presence of an embryo, may give a biased picture of overall eggshell thickness in an individual bird population, and so may fail to identify the actual sources of variation in eggshell thinning. This potential bias may be of less importance in studies of larger sets of eggshells, representing a large number of species and analysed from the phylogenetic standpoint (e.g., Rahn and Paganelli 1989; Maurer et al. 2012). However, in studies assessing the variation in shell thickness in individual species (e.g., Burnett et al. 2013; Morales et al. 2013), the equal a priori treatment of all deserted or intact eggs (non-embryonated ones and representing various stages of embryo development) may prevent the detection of the actual sources of changes. Furthermore, since we found that equator shell thickness (but not blunt end shell thickness) showed a progressive significant decrease with increasing clutch size, another important problem in studies of eggshell variation is to ascertain which part of an egg was measured, and what was the actual clutch size.

With regard to the recent important remarks by Maurer et al. (2012) on the measurement of avian eggshells and the relatively large contribution of various defects (remnants of dried egg content), which affect the proper measurement of shell thickness, some methodological aspects of our analysis of Reed Warbler eggs should be commented upon. First, the Reed Warbler eggs were sampled in the field at various times after laying, so their contents were subject to a certain degree of dehydration. Our shell measurements included the inner membrane, and this structural element of an egg could have been subjected to variable deterioration due to drying, especially at the blunt end, where the air sac is located. Indeed, our results did not confirm the finding of Maurer et al. (2012), who reported that shells were generally thicker at the equator (established from museum eggs) compared to the blunt end in 16 of 40 bird families studied (including Sylvia warblers) or of equal thickness in both these egg regions. In contrast, we observed an inverse relationship: both eggs without visible embryos and eggs with visible embryos had significantly thinner shells at the equator than at the blunt end. More importantly, our results agree with the findings of Gosler et al. (2005), who reported that in eggs of the Great Tit Parus major the shells were thinner (measured without shell membranes) at the shoulder (i.e., the equatorial thickness in the sense of our study) compared to the blunt end. Therefore, considering this large disparity in regional shell thickness variation, it should be stressed that the results of Maurer et al. (2012) are not universal for all bird species, and a more thorough analysis based on a large sample of eggs may reveal a deviation from the general eggshell thickness pattern for individual species. Additionally, our shell thickness values seem to be greater when compared with the (scarce) data for the Reed Warbler and related Acrocephalus warblers with a similar body size presented by Maurer et al. (2012). These discrepancies indicate the need for further studies to assess regional and/or long-term changes (with historical collections with labelled data) in shell thickness in individual bird species based on a large set of eggs varying in developmental stage.

To conclude, our findings show that studies aiming to assess variation in eggshell thickness need to take the developmental status of eggs into consideration. Comparison of eggshell thickness data without checking for the presence of embryos, can give a biased picture of overall eggshell thickness in an individual bird population. On the other hand, our study indicates that the eggshell thickness at the blunt end of an egg is a relatively reliable estimator of shell thickness, irrespective of embryonic development.

Acknowledgments We are grateful to Giulia Cassasole, Justyna Chachulska, Monika Czuchra, Paulina Turowicz, and Katarzyna Turzańska for their help in the field. Dr Richard Broughton, Dr Stephan Schoech, and anonymous reviewers kindly provided some valuable comments and corrected the English. The research was financially supported by the University of Wrocław (projects 1018/S/ IZ/2010-11 and 1073/S/SORM/2012-13). All procedures regarding this study were conducted in compliance with Polish legislation. The permits for conducting a study involving a protected species in a nature reserve were issued by the Regional Directorate for Nature Conservation (Wrocław, Poland). Licenses for bird ringing were issued by the Ornithological Station of the Polish Academy of Sciences based on decisions of the Polish Ministry of Environment.

Open Access This article is distributed under the terms of the Creative Commons Attribution 4.0 International License (http://crea tivecommons.org/licenses/by/4.0/), which permits unrestricted use, distribution, and reproduction in any medium, provided you give appropriate credit to the original author(s) and the source, provide a link to the Creative Commons license, and indicate if changes were made.

\section{References}

Anderson DW, Hickey J (1970) Oological data on egg and breeding characteristics of Brown Pelicans. Wilson Bull 82:14-28

Balkan M, Karakas R, Biricik M (2006) Changes in eggshell thickness, shell conductance and pore density during incubation in the Peking duck (Anas platyrhynchos f. dom.). Ornis Fenn 83:117-123

Bennett RS (1995) Relative sensitivity of several measures of eggshell quality to the stage of embryonic development. Bull Environ Contam Toxicol 54:428-431

Birkhead TR, Hall J, Schut E, Hemmings N (2008) Unhatched eggs: methods for discriminating between infertility and early embryo mortality. Ibis 150:508-517 
Booth DT (1989) Regional changes in shell thickness, shell conductance, and pore structure during incubation in eggs of the Mute swan. Physiol Zool 62:607-620

Booth DT, Seymour RS (1987) Effect of eggshell thinning on water vapor conductance of Malleefowl eggs. Condor 89:453-459

Bunck CM, Spann J, Pattee O, Fleming W (1985) Changes in eggshell thickness during incubation: implications for evaluating the impact of organochlorine contaminants on productivity. Bull Environ Contam Toxicol 35:173-182

Burnett LJ, Sorenson K, Brandt J, Sandhaus E, Ciani D, Clark M, David C, Theule J, Kasielke S, Risebrough R (2013) Eggshell thinning and depressed hatching success of California Condors reintroduced to Central California. Condor 115:477-491

Burnham WA, Enderson J, Boardman T (1984) Variation in peregrine falcon eggs. Auk 101:578-583

Castilla AM, Herrel A, Díaz G, Francesch A (2007) Developmental stage affects eggshell-breaking strength in two ground-nesting birds: the partridge (Alectoris rufa) and the quail (Coturnix japonica). J Exp Zool 307A:471-477

Castilla AM, Herrel A, Robles H, Malone J, Negro J (2010) The effect of developmental stage on eggshell thickness variation in endangered falcons. Zoology 113:184-188

Deeming DC (2002) Embryonic development and utilisation of egg components. In: Deeming DC (ed) Avian incubation: behaviour, environment and evolution. Oxford University Press, Oxford, pp 63-87

Eeva T, Lehikoinen E (1995) Egg shell quality, clutch size and hatching success of the great tit (Parus major) and the pied flycatcher (Ficedula hypoleuca) in an air pollution gradient. Oecologia 102:312-323

Falk K, Møller S (1990) Clutch size effects on eggshell thickness in the Peregrine falcon and European Kestrel. Ornis Scand 21:265-269

Finnlund M, Hissa R, Koivusaari J, Merilä E, Nuuja I (1985) Eggshells of arctic terns from Finland-effects of incubation and geography. Condor 87:79-86

Gosler AG, Higham JP, Reynolds J (2005) Why are birds' eggs speckled? Ecol Lett 8:1105-1113

Halupka L, Dyrcz A, Borowiec M (2008) Climate change affects breeding of Reed warblers Acrocephalus scirpaceus. J Avian Biol 39:95-100

Halupka L, Halupka K, Klimczuk E, Sztwiertnia H (2014a) Coping with shifting nest predation refuges by European Reed warblers Acrocephalus scirpaceus. PLoS One 9(12):e115456. doi:10. 1371/journal.pone.0115456

Halupka L, Sztwiertnia H, Borowiec M, Klimczuk E, Leisler B (2014b) Lack of polygyny in Central European populations of Reed warblers Acrocephalus scirpaceus. Ornis Fenn 91:187-194

Handrich Y (1989) Incubation water loss in King penguin egg. I. Change in egg and brood pouch parameters. Physiol Zool 62:96-118

Hargitai R, Mateo R, Török J (2011) Shell thickness and pore density in relation to shell colouration, female characteristics, and environmental factors in the Collared flycatcher Ficedula albicollis. J Ornithol 152:579-588

Hemmings N, West M, Birkhead T (2012) Causes of hatching failure in endangered birds. Biol Lett 8:964-967

Hoffman DJ, Rattner B, Burton G, Cairns J (2003) Handbook of ecotoxicology, 2nd edn. Lewis Publishers, Boca Raton

Hoyt DF (1979) Practical methods of estimating volume and fresh weight of bird eggs. Auk 96:73-77

Hurlbert SH (1984) Pseudoreplication and the design of ecological field experiments. Ecol Monogr 54:187-211

Jagannath A, Shore R, Walker L, Ferns P, Gosler A (2008) Eggshell pigmentation indicates pesticide contamination. J Appl Ecol 45:133-140
Karlsson O, Lilja C (2008) Eggshell structure, mode of development and growth rate in birds. Zoology 111:494-502

Kern MD, Cowie R, Yeager M (1992) Water loss, conductance, and structure of eggs of pied flycatchers during egg laying and incubation. Physiol Zool 65:1162-1187

Klimczuk E, Halupka L, Czyż B, Borowiec M, Nowakowski JJ, Sztwiertnia H (2015) Factors driving variation in biparental incubation behaviour in the Reed warbler (Acrocephalus scirpaceus). Ardea 103:51-59. doi:10.5253/arde.v103i1.a5

Koenig WD (1982) Ecological and social factors affecting the hatchability of eggs. Auk 99:526-536

Król E (1984) Wykluczanie się żerowisk samca i samicy trzcinniczka (Acrocephalus scirpaceus) w okresie karmienia piskląt. Ptaki Śląska 3:48-53

Mänd R, Tilgar V (2003) Does supplementary calcium reduce the cost of reproduction in the pied flycatcher Ficedula hypoleuca? Ibis 145:67-77

Maurer G, Portugal S, Miks I, Cassey P (2011a) Speckles of cryptic black-headed gull eggs show no mechanical or conductance structural function. J Zool 285:194-204

Maurer G, Portugal S, Boomer I, Cassey P (2011b) Avian embryonic development does not change the stable isotope composition of the calcite eggshell. Reprod Fertil Dev 23:339-345

Maurer G, Portugal S, Cassey P (2012) A comparison of indices and measured values of eggshell thickness of different shell regions using museum eggs of 230 European bird species. Ibis 154:714-724

Miljeteig C, Gabrielsen G, Strøm H, Gavrilo M, Lie E, Jenssen B (2012) Eggshell thinning and decreased concentrations of vitamin $\mathrm{E}$ are associated with contaminants in eggs of ivory gulls. Sci Total Environ 431:92-99

Morales J, Ruuskanen S, Laaksonen T, Eeva T, Mateo R, Belskii E, Ivankina E, Järvinen A, Kerimov A, Korpimäki E, Krams I, Mänd R, Morosinotto C, Orell M, Qvarnström A, Siitari H, Slater F, Tilgar V, Visser M, Winkel W, Zang H, Moreno J (2013) Variation in eggshell traits between geographically distant populations of pied flycatchers Ficedula hypoleuca. J Avian Biol 44:111-120

Odsjö T, Sondell J (2014) Eggshell thinning of osprey (Pandion haliaetus) breeding in Sweden and its significance for egg breakage and breeding outcome. Sci Total Environ 470:1023-1029

Potti J, Merino S (1996) Causes of hatching failure in the Pied flycatcher. Condor 98:328-336

Pulliainen E, Marjakangas A (1980) Eggshell thickness in eleven sea and shore bird species of the Bothnian Bay. Ornis Fenn 57:65-70

Rahn H, Paganelli CV (1989) Shell mass, thickness and density of avian eggs derived from the tables of schönwetter. J Ornithol 130:59-68

Reynolds SJ (2001) The effects of low dietary calcium during egglaying on eggshell formation and skeletal calcium reserves in the Zebra Finch Taeniopygia guttata. Ibis 143:205-215

Reynolds SJ, Perrins C (2010) Dietary calcium availability and reproduction in birds. Curr Ornithol 17:31-74

Risebrough RW (1986) Pesticides and bird populations. Curr Ornithol 3:397-427

Rothstein SI (1972) Eggshell thickness and its variation in the Cedar waxwing. Wilson Bull 84:469-474

Snyder NFR, Meretsky V (2003) California condors and DDE-a reevaluation. Ibis 145:136-151

Sotherland PR, Packard G, Taigen T, Boardman T (1980) An altitudinal cline in conductance of cliff swallow (Petrochelidon pyrrhonota) eggs to water vapor. Auk 97:177-185

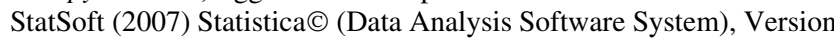
7.1., Tulsa, USA

Stewart IRK, Westneat D (2013) Patterns of hatching failure in the House Sparrow Passer domesticus. J Avian Biol 44:69-79 